\title{
Atomic Resolution Microscopy
}

National Cancer Institute

\section{Source}

National Cancer Institute. Atomic Resolution Microscopy. NCI Thesaurus. Code C20346.

Several related technologies for imaging and measuring surfaces on a fine scale, down to the level of molecules and groups of atoms. These technologies share the concept of scanning an extremely sharp tip (3-50 nm radius of curvature) across the object surface. The tip is mounted on a flexible cantilever, allowing the tip to follow the surface profile. When the tip moves in proximity to the investigated object, forces of interaction between the tip and the surface influence the movement of the cantilever. Various interactions can be studied depending on the specific mechanics of the probe. Specialized sensors detect and record the movements of the cantilever, providing an image with resolution at the atomic level. 